\title{
The Research on Value Network Reconstruction of Liquor Industry through Value Co-creation
}

\author{
Pu Yang \\ School of Management and Economics \\ University of Electronic Science and Technology of China \\ Chengdu, China \\ 15528366796@163.com
}

\author{
Lei Liu \\ School of Management and Economics \\ University of Electronic Science and Technology of China \\ Chengdu, China \\ liuleibox@163.com
}

\begin{abstract}
The reconstruction of value network is an inevitable path for the transformation and upgrading of liquor industry. Through the analysis of the composition of value network in liquor industry, this paper gives vertical analysis and horizontal analysis of the value network, and puts forward Value Co-creation based on industrial convergence, which is took part by value chain, including producers, consumers, and the whole value chain. And this paper uses liquor industry and the integration of tourism as an example to analyze Value Co-creation based on the industrial convergence. It provides a train of thought for Value Network Reconfiguration of liquor industry, as well as its transformation and upgrading.
\end{abstract}

Keywords-liquor industry; value network; industry chain; industrial convergence; value co-creation

\section{INTRODUCTION}

At present, with the development of Internet economy, traditional industries are facing the subversion of Internet. The rapid development of mobile Internet has accelerated the trend of subversion in all traditional industries. The cross-border Internet industry is reshaping the traditional industrial pattern and profoundly changing its previous mode of operation. Under the new normal, affected by the macroeconomy and the "eight provisions" and other policy restrictions, alcohol consumption lost the brilliant "golden decade" and gradually returned to rational. Removed the deformity of the bubble, the liquor industry in the future growth of the new growth path will undoubtedly be the real value of the industry to create the core. As the representative of the traditional industries, the liquor industry, subject to the traditional thinking, has always regarded the brewing of wine as the core resource and the core of "producer" rather than "consumer" as its value creation, and the main means of value transmit was based on the single-dimensional value chain in transaction process. However, with the advent of the Internet era, consumers' lifestyles, consumer psychology, access to information and value appeals have changed dramatically, the original value network of the traditional liquor industry is facing a collapse. Under the new economic normal that liquor is no longer scarce, the consumption structure is changed and the channels are no longer aggregated, the liquor industry urgently needs to construct the value creation logic of "Internet +", explore the innovation of business models and build a new value network to realize the development of liquor industry in transformation

The Social Science Planning Project of Sichuan Province(SC16BJ003) and upgrading under the new normal.

\section{RESEARCH TRENDS}

With the subversion of the Internet to the traditional industries, business transformation has become a hot topic in economic research. The industrial development under the new normal has aroused widespread concern of scholars. Aiming at the liquor industry, many scholars have done a great deal of research on the transformation and upgrading of the liquor industry under the new normal from the perspectives of industrial deepening, industrial integration and industrial expansion. From the point of view of industry deepening, Feng Lin et $\mathrm{al}^{[1]}$. (2013) pointed out that in the pattern of industrialization dominated by regional competition, the cluster brand represented by the leading wine enterprises should be built to continuously enhance the added value of the industry so as to achieve the goal of industrial deepening. From the perspective of industrial integration, Jun Kang ${ }^{[2]}$ (2012), Daohong Wang ${ }^{[3]}$ (2014), Qifeng Wang ${ }^{[4]}$ (2014) and Feng $\operatorname{Lin}^{[5]}$ (2013) studied the integration of traditional liquor industry with high-tech industries and the integration of liquor industry and tourism, and proposed that forming the industry linkage based on industry convergence, leading the electricity supplier industry, logistics industry and the financial industry, and continue to extend to more industries. From the perspective of industrial expansion, most researches focus on the development of industrial clusters, Shumeng Zhang et al. ${ }^{[6]}$ (2013) proposed to build a liquor cluster brand in response to the development of the liquor industry cluster in Sichuan Province and put forward countermeasures for establishing a liquor concentration area in Sichuan Province. Liping Mao ${ }^{[7]}$ (2016) defined the liquor industry chain as an industry that is directly or indirectly related to the process of liquor production, processing, and final marketing in a certain region or space, and also provided suggestions for the industrial cluster of Luzhou Laojiao.

Although the above studies all pointed out that in the context of the rapid development of the Internet, the transformation and upgrading are the inevitable choices for maintaining the economic growth of liquor industry, but the specific path of transformation and upgrading is not clear. Starting from the microscopic level of enterprise transformation, Yinbao Yang et al. ${ }^{[8]}$ (2014) argue that the liquor enterprises can implement the transformation in ten major aspects and shift their emphasis from "safeguarding 
distributors' interests" to "customer value research." The study of a number of issues by Bangchang Liang ${ }^{[9]}$ (2015) on the new normal liquor industry also pointed out that the liquor industry chain should move from a single operation to a two-way operation, put the "consumer" to a more important position. Guocheng $\mathrm{Fu}^{[10]}$ (2012) proposed that liquor enterprise producers should return to rationality and the consumption of liquor by normal people is the motive force for the development of liquor enterprises. All of these studies provide ideas for the value co-creation of liquor industry.

\section{RECONSTRUCTION OF THE LIQUOR INDUSTRY VALUE NETWORK}

The Internet has changed the time, space, content and links to commercial transactions, but also changed the traditional industry value creation logic. As a representative of the traditional industries, the liquor industry has also reconstructed its value network with the advent of the Internet era.
Based on the traditional value network of liquor industry, the reconstructed value network forms a value network consisting of three sub-value networks including the competitor network, the buy-supply network and the symbiosis network. In the buy-supply network, due to its unique characteristics, liquor industry can be divided into three buy-supply networks. They are supplier-enterprise network, enterprise-consumer Network and supplier - enterprise customer Network, which includes offline sales platforms, online sales platforms, raw grain suppliers, energy suppliers, consumables suppliers, information, technology and logistics; Network, which contains beer, wine and foreign wine such as $\mathrm{XO}$; in the symbiosis network, which includes the sports industry, advertising industry, entertainment industry, insurance industry, the value of creating the main body; in the entire value network , Government, education and financial institutions or industries also play a supporting role in the network. As shown in Fig. 1

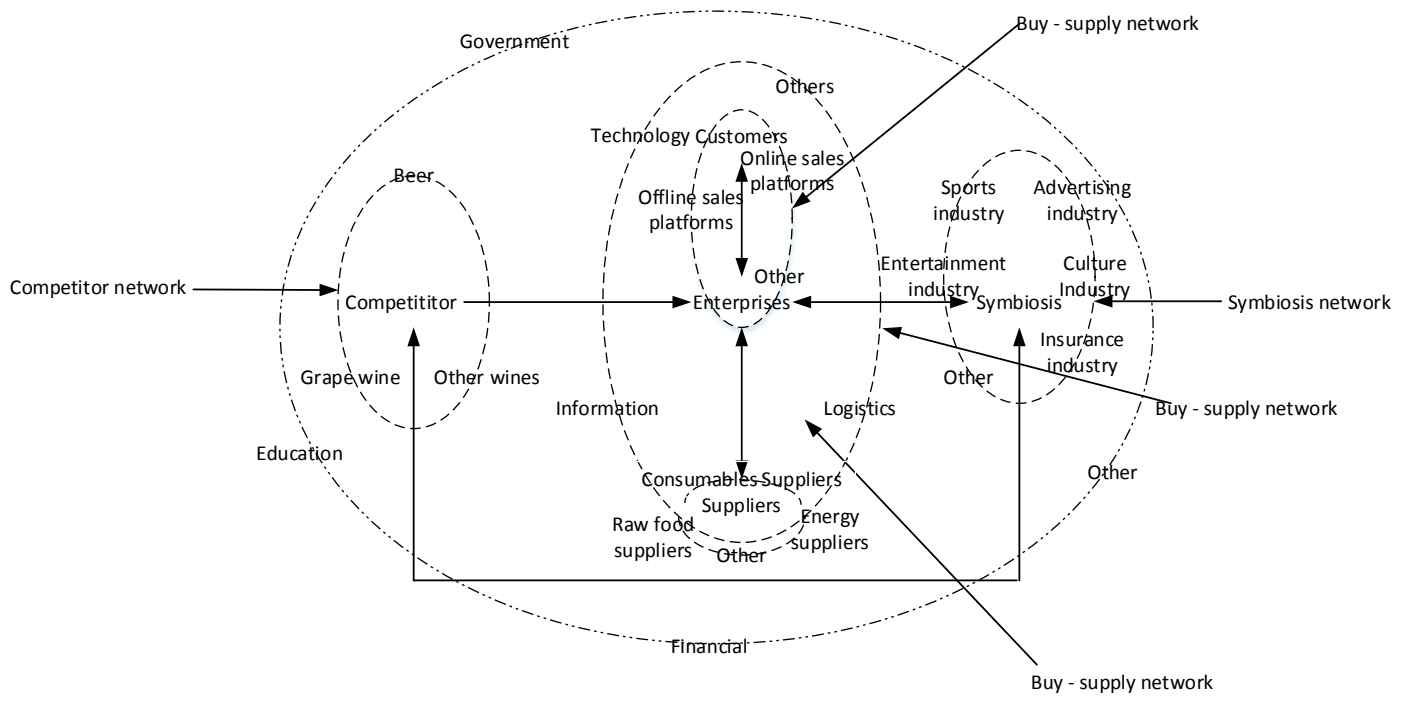

Fig. 1. Liquor industry value network diagram

As we can see from Table1, the vertical network is the result of the value creation of the liquor industry's value chain, while the horizontal network is the result of the integration of the liquor industry. The following will be based on industrial chain and industry integration value of the entire value of the network to create behavior analysis.

\section{ANALYSIS OF VALUE CREATION OF LIQUOR INDUSTRY BASED ON INDUSTRY CHAIN}

A series of policies such as "wine restriction order" and "restriction of public sanctions" made the liquor industry end its decade of gold development with a growth rate of only $3.23 \%$ in 2016. In order to seek new profit growth points, many liquor enterprises have successively transformed "Touch the net." With the advent of the Internet age, low-cost interactions between people have become possible and it has become possible for producers and consumers and other participants in the value chain to jointly create value. For liquor industry, it also gradually by producer-centric value creation, and gradually shift to consumer-centered value creation.

\section{A. Producer - Centered Liquor Industry Value Analysis}

In the producer-centered logic, value creation is the value creation by the producer with value creation as its starting point In order to realize its own value goal, liquor enterprises should create value through various kinds of tangible and intangible resources so as to improve their business performance and brand value. Producer-centered value creation, most of the liquor companies independently developed new products, ignoring the consumer's value demands. Today, with the popularization of the Internet, this traditional mode of value creation can no longer meet the diversified and individual needs of consumers and is bound to be replaced by a new mode of value creation.

\section{B. Consumers as the center of the liquor industry to create value analysis}

In the consumer-centered logic, value creation is the starting point for consumers in their own interests. At present, among the liquor enterprises, there are few enterprises that create values based on the consumers in an all-round way. 
However, in recent years, the liquor industry has moved from producer-centered to consumer-centered. Taking Luzhou Laojiao as an example, the "altar wine in life" mobilized the enthusiasm of consumers through the model of "emotion + wine" and became a new profit growth point of Luzhou Laojiao. For liquor companies to create the value of consumer-centered now generally reflected in the custom wine, altar wine, concept wine and experience activities in four types.
The following table from typical examples, value propositions, input elements of consumers, interactive platform for enterprises and enterprises, the interaction between enterprises and enterprises, the form of interaction between enterprises and customers, the aspects of customer participation in business operations and customer participation, Four kinds of consumer-centered value creation types were analyzed.

TABLE I. LIQUOR COMPANIES COMMON FOUR CONSUMER-CENTRIC VALUES TO CREATE TYPE ANALYSIS TABLE

\begin{tabular}{|c|c|c|c|c|c|c|c|}
\hline Type & Typical example & Value proposition & $\begin{array}{l}\text { Consumer } \\
\text { input } \\
\text { elements }\end{array}$ & $\begin{array}{l}\text { Customer } \\
\text { interaction } \\
\text { platform }\end{array}$ & $\begin{array}{l}\text { Form of } \\
\text { interaction for } \\
\text { customer to } \\
\text { enterprise } \\
\end{array}$ & $\begin{array}{l}\text { Customer } \\
\text { participation in the } \\
\text { operation of the link }\end{array}$ & $\begin{array}{c}\text { Customer } \\
\text { participation }\end{array}$ \\
\hline $\begin{array}{l}\text { The wine for } \\
\text { make to order }\end{array}$ & $\begin{array}{c}\text { 'That altar wine in } \\
\text { life' for Luzhou } \\
\text { Laojiao }\end{array}$ & $\begin{array}{l}\text { Consumer demand } \\
\text { for personalization }\end{array}$ & $\begin{array}{l}\text { Time } \\
\text { enthusiasm }\end{array}$ & Offline & $\begin{array}{l}\text { Face to face } \\
\text { interaction }\end{array}$ & $\begin{array}{c}\text { Participate in } \\
\text { marketing and sales }\end{array}$ & General \\
\hline $\begin{array}{l}\text { Sealing altar } \\
\text { wine }\end{array}$ & $\begin{array}{l}\text { Blue classic altar } \\
\text { wine }\end{array}$ & $\begin{array}{l}\text { Consumer demand } \\
\text { for sharing, identity } \\
\text { show }\end{array}$ & Knowledge & $\begin{array}{l}\text { Cloth altar } \\
\text { ceremony }\end{array}$ & $\begin{array}{l}\text { Face to face } \\
\text { interaction }\end{array}$ & $\begin{array}{c}\text { Participate in } \\
\text { customization and } \\
\text { sale }\end{array}$ & Higher \\
\hline Concept wine & Jiang white wine & $\begin{array}{c}\text { Consumer } \\
\text { self-concept, } \\
\text { emotional appeal }\end{array}$ & Creative & $\begin{array}{c}\text { Online } \\
\text { community }\end{array}$ & $\begin{array}{l}\text { Interact with each } \\
\text { other }\end{array}$ & $\begin{array}{l}\text { Participate in new } \\
\text { product development }\end{array}$ & Higher \\
\hline $\begin{array}{l}\text { Experience } \\
\text { activities }\end{array}$ & Shuijingang & $\begin{array}{c}\text { Customer service } \\
\text { needs }\end{array}$ & Time & $\begin{array}{l}\text { Offline } \\
\text { platform }\end{array}$ & Point interaction & Feedback & General \\
\hline
\end{tabular}

It can be seen from Table 1 that in the dual context of the advent of the Internet era and the rapid development of personalized demand in the consumer market, consumer-centered value creation has drawn the attention of liquor enterprises. However, most of these values are created through interaction with each other, while there is very little creative interaction represented by interaction. Therefore, in the future value creation of liquor enterprises, consumers should be actively involved in the operation of enterprises, and efforts should be made to increase the level of customer participation so as to integrate consumers' value propositions and emotional appeals into products so as to satisfy consumers personalized demand, and thus improve their own competitiveness.

\section{ANALYSIS ON THE VALUE OF LIQUOR INDUSTRY BASED ON INDUSTRY CONVERGENCE}

\section{A. Industry integration to create value}

The phenomenon of industrial convergence began to appear in the 1970s. The main manifestation was the gradual blurring or ablation of the original fixed boundaries between the two industries and the integration at the boundary between industries and even the development of new industrial forms. Phenomenon is called industrial integration. Initially, industry convergence mainly appeared in the field of computer and communications, and later expanded to service industries such as finance and logistics, and gradually expanded into manufacturing and agriculture. This convergence of industries taking the rapid development and diffusion of hi-tech as the core of information technology as the turning point has become the major growth point of industrial value and the most dynamic source and driving force for economic growth. Therefore, in recent years, domestic and foreign scholars have conducted in-depth research on this phenomenon and formed a preliminary theory of industrial integration.

For liquor industry, its brewing process not only condenses the core memory culture, but also condenses the consumer culture. In recent years, with the rapid development of the Internet, the material culture and consumer culture of the liquor industry have become more and more integrated. Liquor culture has become an integral part of the added value of Liquor, selling wine is selling culture has gradually evolved into a hidden rules of the liquor market. For the tourism industry, its infinite extension and uncertainty make it a borderless industry. In addition, the drive for soft elements and the expansion of the Van Baillen effect have also broadened the boundaries of the tourism industry. With the borderless tourism industry and the liquor industry culture becoming the core competitiveness of the liquor industry, the dual integration of tourism and liquor industry has become possible.

\section{B. Ways to Build Liquor Industry Based on Industry Convergence - Taking Tourism Industry as an Example}

Starting from the value of liquor, the value of liquor is subdivided into two levels of material and spiritual value system. Among them, the material value mainly refers to the use value and collection value of liquor. Mental values refer to cultural values, conceptual values, and experiential values, respectively. 
TABLE II.

LIQUOR VALUE TABLE

\begin{tabular}{c|c|c|c}
\hline \hline \multirow{4}{*}{$\begin{array}{c}\text { Value for } \\
\text { Liquor }\end{array}$} & \multirow{2}{*}{ Material value } & Value in use & Liquor products \\
\cline { 3 - 4 } & \multirow{3}{*}{ Spiritual value } & Value in collection & Liquor products \\
\cline { 3 - 4 } & \multirow{2}{*}{ Value in culture } & Traditional culture for Liquor \\
\cline { 3 - 4 } & & & Regional culture for Liquor \\
\cline { 3 - 4 } & \multirow{2}{*}{ Value in concept } & Liquor brewing site \\
\cline { 3 - 4 } & \multicolumn{2}{|c|}{ Value in experience } & Liquor products \\
\cline { 3 - 4 } & & \multicolumn{2}{c|}{ Liquor brewing process } \\
\hline
\end{tabular}

As shown in Table 2, for the sake of white wine, its use value refers to the value it brings consumers after tasting, such as the practical value of white wine itself; the value of collection refers to the storage of liquor due to scarcity, etc. Consumer value; cultural value refers to the cultural characteristics of liquor, cultural connotation and cultural personality and so on to the consumer value; concept of value refers to the different types of liquor from the concept of value to the consumer , For example, Jiang Xiaobai bring consumers the concept of youth; experiential value refers to the value brought to consumers by visiting the process of making liquor and using liquor.

For the tourism industry, tourism itself is a comprehensive industry. It consists of six traditional elements of food, housing, transportation, tourism, shopping and entertainment. It is a very large integrated entity. For the tourism industry, it must recognize the tourism industry has a strong backing, dependence and dependence on a large number of industries and industries. Its development must be inseparable from the support, promotion and cooperation of all trades and industries. The types of tourism products can be mainly classified into tourism type, vacation type and special line type. Different products correspond to different leading value elements, which can be divided according to the dominant factors and their respective types to more accurately grasp consumer psychology and behavior purpose.

\section{C.Analysis on the Value of Liquor Industry and Tourism Integration}

Liquor industry and tourism apparently belong to the traditional industries, but with the advent of the Internet era, the product economy and service economy can no longer meet the increasing individual needs of consumers, experience economy also came into being. The combination of the borderless nature of tourism and the experience economy of the liquor industry has created a huge impetus to make tourism and liquor industries increasingly integrate. In addition, consumers are not only the material needs for tastings and collections, but also the simple demand for tourism to meet the traditional needs of the six elements instead of the deeper needs and the potential demand for development. This has also promoted the integration of the two industries and innovative ways of integration.

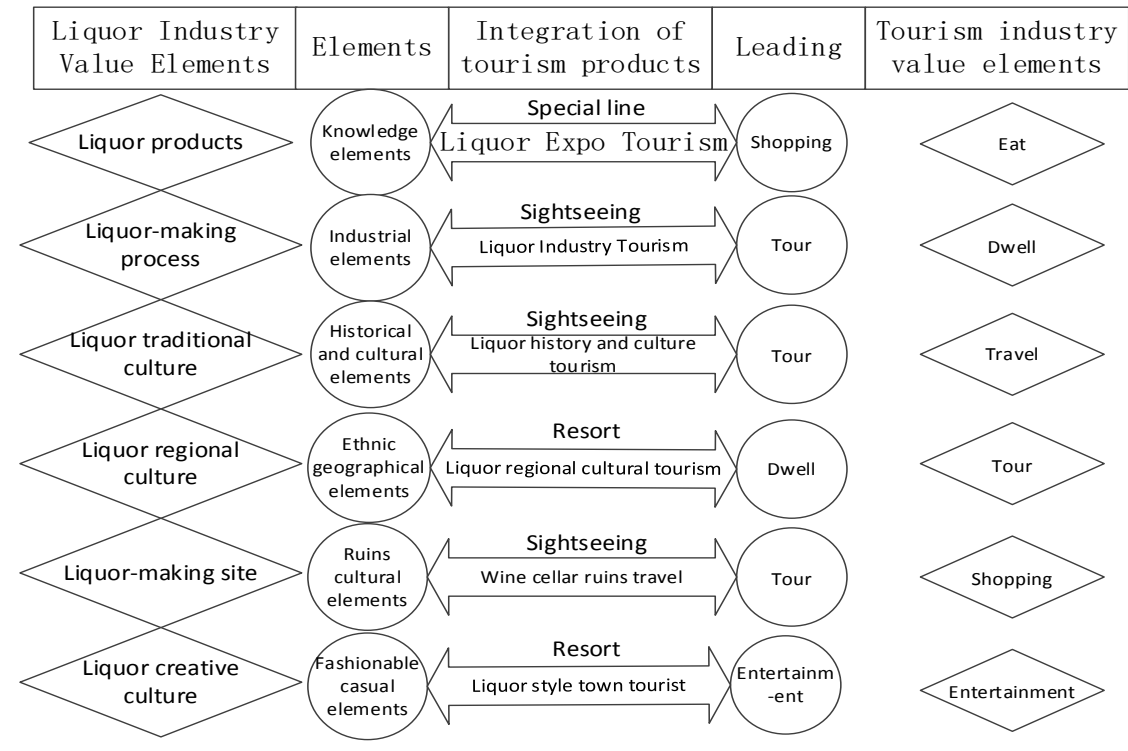

Fig. 2. Liquor industry and tourism industry integration diagram

In addition to the macroscopic factors such as the external force of the government, the main reason for the integration of liquor industry and tourism industry is that their integrated products can meet the needs of consumers, then form value co-creation with consumers, and realize the integration between liquor industry and tourism The value of creating, valuable is the essence of the driving force. The way of integration is shown in Fig. 2. 
There are mainly six types of fusion products formed by "liquor + tourism" integration industry: white wine exposition tourism, white liquor industry tourism, white wine history culture tourism, white wine regional culture tourism, wine cellar heritage tourism and liquor town style tourism. In the previous article, the value elements of liquor industry were classified into physical value and spiritual value, which included food value, collectible value, cultural value, concept value and experiential value. These two main categories of value were mainly carried on liquor products, liquor making process, liquor tradition Culture, liquor regional culture, Liquor brewing sites and Liquor creative culture. For the tourism industry, there are six main points of value: food, housing, transportation, tourism, shopping and entertainment. Liquor industry and tourism provide their abilities and resources according to the needs of consumers and their potential demand. The liquor industry chooses the dominant value elements according to the resources and abilities it has and integrates with the six major value-leading elements of the corresponding tourism industry Fusion products.

\section{CONCLUSION}

Based on the theory of value network, this paper studies the composition of value network in liquor industry, and studies the value creation in value network based on industry chain and industry convergence. Different from the previous research on industrial transformation and upgrading, based on the value creation of the liquor industry, this study, based on the value network of the liquor industry, provides a new perspective for the transformation of liquor industry through vertical analysis and horizontal analysis of the liquor industry value network.

\section{REFERENCES}

[1] Feng Lin. Liquor industry should be multi-industry linkage development [J]. Stock market dynamics analysis, 2013,(48):50-51(In Chinese).

[2] Jun Kang. On Tourism Development Strategy of "Chinese White Wine Golden Triangle" Based on Sichuan Wine Culture [J]. Journal of Sichuan University of Science and Technology (Social Sciences Edition).2012, 27(01):65-67 In Chinese).

[3] Daohong Wang. Maotai liquor culture and tourism development [D]. Central China Normal University, 2014(In Chinese).

[4] Qifeng Wang. Experience and Countermeasures of Experience Marketing of High-end Liquor Enterprises in Sichuan [J]. Brewing, 2014,41(05):15-19(In Chinese).

[5] Feng Lin. Industry's Industrial Prospects - The Future Trend of Chinese Liquor Industry [J]. Chinese liquor, 2012,(02):44-49(In Chinese).

[6] Shu-Meng Zhang, Yi-Hong Gu, Qi Wang, Yun-Xia Guo, Kun-Yi liu. oncept and Development of Sichuan Liquor Concentration Area [J]. Chinese Brewing, 2013, 32(10):157-159(In Chinese).

[7] Liping Mao. Luzhou liquor industry park competitiveness [D]. Chongqing Normal University, 2016.

[8] YinBao Yang. Liquor enterprises should be changed in time to achieve a transitional transition [J]. Brewing Technology, 2014,(10):137-140(In Chinese).

[9] Bangchang Liang, Songgui He, Chunping Xu. Discussion on Some Problems of Liquor Industry under the New Normal. Brewing, 2015, 42(06):2-6(In Chinese).

[10] Guocheng Fu. Chinese liquor industry should focus on the rational upgrading and corporate culture to form a resonance [J]. Brewing, 2012, 39(05):99-103(In Chinese). 